\title{
Manganese Catalyzed Asymmetric Transfer Hydrogenation of Ketones Using Chiral Oxamide Ligands
}

\author{
Jacob Schneekönig \\ Kathrin Junge (1) \\ Matthias Beller* (D) \\ Leibniz-Institut für Katalyse e.V., Albert-Einstein-Str. 29a, \\ 18059 Rostock, Germany \\ Matthias.Beller@catalysis.de \\ Published as part of the 30 Years SYNLETT - Pearl Anniversary \\ Issue
}
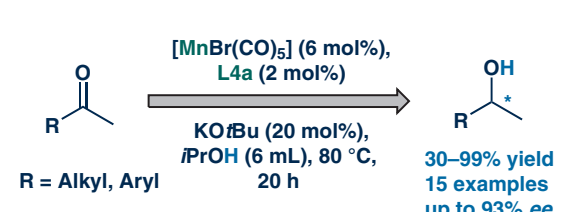

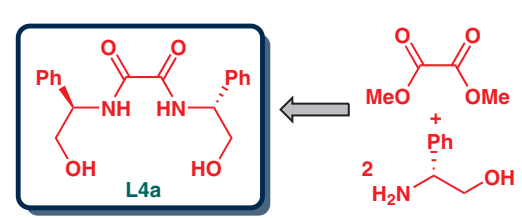

Received: 14.12.2018

Accepted after revision: 10.01.2018

Published online: 25.01 .2019

DOI: 10.1055/s-0037-1611669; Art ID: st-2018-b0806-I

License terms: cc)

Abstract The asymmetric transfer hydrogenation of ketones using isopropyl alcohol (IPA) as hydrogen donor in the presence of novel manganese catalysts is explored. The selective and active systems are easily generated in situ from $\left[\mathrm{MnBr}(\mathrm{CO})_{5}\right]$ and inexpensive $C_{2}$-symmeric bisoxalamide ligands. Under the optimized reaction conditions, the Mn-derived catalyst gave higher enantioselectivity compared with the related ruthenium catalyst.

Key words transfer hydrogenation, asymmetric, manganese, chiral ligands, ketones

Enantiomerically pure alcohols are of significant importance for the pharmaceutical, fine-chemical and fragrance industries. Although numerous precious-metal complexes have been reported for the asymmetric reduction of carbonyl compounds, there is a continuing interest in the development of less expensive, more efficient catalysts. In addition to classic hydrogenations, the asymmetric transfer hydrogenation (ATH) of prochiral ketones represents a convenient approach towards enantiomerically enriched alcohols. In recent years, remarkable progress has been made in replacing noble metals such as ruthenium or iridium with more abundant base metals such as iron or cobalt in such transformations. ${ }^{1-4}$

As part of the recent development in homogenous manganese-catalyzed reductions, ${ }^{5,6}$ the first manganese-based catalysts for non-enantioselective transfer hydrogenation have been published by Darcel and Sortais as well as by our group.7 In addition, Kirchner has described a Mn catalyst containing a chiral ferrocenyl-based pincer ligand for ATH of ketones, ${ }^{8}$ which produced the corresponding alcohols with up to $85 \%$ ee. Very recently, Morris and co-workers published a manganese pincer complex that enables the ATH of aromatic ketones with up to $53 \% e e .{ }^{9}$ The group of Sortais could show that the combination of $\left[\mathrm{MnBr}(\mathrm{CO})_{5}\right]$ and a chiral diamine ligand is capable of catalyzing the ATH of aromatic ketones with up to $90 \% e e .^{10}$ Notably, asymmetric hydrogenations using manganese pincer complexes were reported by Clarke and co-workers as well as by our group. ${ }^{11}$ While the replacement of precious catalyst metals by non-noble metals is intensively studied, considerably less effort has focused on the development of readily available and less sensitive ligands. Here, many catalysts derived from $\mathrm{Fe}, \mathrm{Mn}$ or $\mathrm{Co}$ and P-based pincer ligands provide outstanding catalytic performance, but most of their ligands are very expensive, often not commercially available and/or air-sensitive. In this respect, the application of phosphorusfree and easy accessible ligand systems is highly desired and would be a clear advantage for any possible application from an economic point of view.

Therefore, we started a program to identify active nonphosphorous-based manganese catalyst systems for ATH. As model substrates we chose an aromatic (acetophenone) and an aliphatic (cyclohexyl methyl ketone) ketone. For convenience, in the initial activity screening, the catalyst was derived in situ from a combination of the metal precursor $\left[\mathrm{MnBr}(\mathrm{CO})_{5}\right]$ and chiral amine derivatives. Remarkably, in the presence of Jacobsen's ligand $\mathbf{L} \mathbf{1}$ the ATH of acetophenone proceeded with $36 \%$ ee (Table 1 , entry 1 ). Therefore, we tested other multidentate ligands, specifically chiral oxamides L3-L7, ${ }^{12,13}$ which were varied with respect to their electronic and steric properties (Figure 1). Advantageously, L3-L7 are easy accessible by amidation of dimethyl oxalate with various amino alcohols. ${ }^{14,15}$ Nevertheless, to our knowledge, this type of ligand has never been tested in asymmetric reductions to date. 
<smiles>CC(C)(C)c1cc(C=NC2CCCCC2N=Cc2cc(C(C)(C)C)c(O)c(C(C)(C)C)c2)c(O)c(C(C)(C)C)c1</smiles><smiles>c1ccc(-c2ccc3ccccc3c2NPC2CCCCC2NPc2c(-c3ccccc3)ccc3ccccc23)cc1</smiles>

L1 $(S, S)$-Jacobsen's ligand

L2a: $\mathrm{R}=\left(\mathrm{CH}_{2}\right)$

L2b: $\mathbf{R}=(\mathrm{C}=\mathrm{O}) ;(S, S)$ Trost ligand L2c: $\mathrm{R}=(\mathrm{C}=0) ;(S, S)$ Trost naphthyl ligan

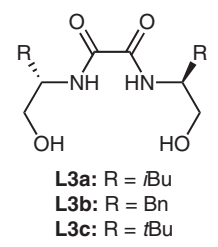<smiles>CCC(NC(=O)C(=O)N[C@@H](CC)c1ccccc1)c1ccccc1</smiles>

L4a: $R=H$
L4b: $R=M e$ L5<smiles>[R]C(NC(=O)C(=O)NC([R])C(O)c1ccccc1)C(O)c1ccccc1</smiles>

L6a: $\mathrm{R}=(S)-\mathrm{Ph}$ L6b: $\mathrm{R}=(R)-\mathrm{Ph}$

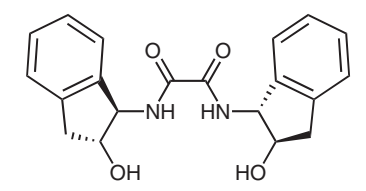

L7

Figure 1 Tested ligands for the manganese-catalyzed ATH of ketones using IPA

As shown in Table 1, manganese catalysts derived from alkyl-, benzyl- or phenyl-substituted $N, N^{\prime}$-bis(2-hydroxyethyl)oxamides $\mathbf{L 3 a - c}$ and $\mathbf{L} \mathbf{4} \mathbf{a}$ achieved only low selectivities in the ATH of the aromatic model compound acetophenone (entries 5-8). The introduction of an additional phenyl group in the $\alpha$-position to the alcohol moiety of the ligand motif (L6a and $\mathbf{L 6 b}$ ) did not result in a significant improvement of the selectivity. Here, $30 \%$ ee were obtained for acetophenone, when the phenyl groups are arranged cis to each other (L6a). The sterically demanding ligand $\mathbf{L 7}$ derived from $(1 R, 2 R)-(-)$-trans-1-aminoindanol was active, but only racemic 1 -phenylethanol was obtained as a product. For comparison, phosphorus containing ligands L2a-c with a related structure motive were also applied for the ATH of acetophenone, leading to moderate activities and poor or no chiral induction (entries 2-4).

Table 1 Ligand Screening for the ATH of Ketones ${ }^{\mathrm{a}}$

$$
\stackrel{\substack{\mathrm{KO} t \mathrm{Bu}, \mathrm{PrOH} \\ 70^{\circ} \mathrm{C}, 16 \mathrm{~h}}}{\stackrel{\left[\mathrm{MnBr}(\mathrm{CO})_{5}\right], \mathrm{L1}-\mathrm{L7}}{\longrightarrow}}
$$

\begin{tabular}{lllccc}
\hline Entry & Ligand & Conv. [\%] & ee [\%] & Conv. [\%] & ee [\%] \\
& \multicolumn{2}{c}{$\mathrm{R}=\mathrm{Ph}$} & \multicolumn{2}{c}{$\mathrm{R}=\mathrm{Cy}$} \\
\hline 1 & L1 & 50 & 36 & 4 & 10 \\
2 & L2a & 65 & 35 & 28 & 24 \\
3 & L2b & 35 & rac. & 0 & -
\end{tabular}

\begin{tabular}{llcccc}
\hline Entry & Ligand & Conv. [\%] & ee [\%] & \multicolumn{2}{c}{ Conv. [\%] } \\
R=Ph & ee [\%] \\
\hline 4 & L2c & 32 & 6 & 0 & - \\
5 & L3a & 63 & 14 & 0 & - \\
6 & L3b & 92 & 10 & 77 & 53 \\
7 & L3c & 40 & 9 & 10 & 20 \\
8 & L4a & 65 & 26 & 43 & 82 \\
9 & L4b & - & - & 15 & rac. \\
10 & L5 & - & - & 15 & rac. \\
11 & L6a & 66 & 30 & 46 & 5 \\
12 & L6b & 25 & 6 & 14 & 25 \\
13 & L7 & 73 & rac. & 73 & 4 \\
\hline
\end{tabular}

a Standard reaction conditions: ketone $(1 \mathrm{mmol}),\left[\mathrm{MnBr}(\mathrm{CO})_{5}\right]$

(0.01 mmol, $1 \mathrm{~mol} \%)$, ligand (0.01 mmol, $1 \mathrm{~mol} \%)$, KOtBu $(0.1 \mathrm{mmol}$, $10 \mathrm{~mol} \%), i \operatorname{PrOH}(5 \mathrm{~mL}), 70^{\circ} \mathrm{C}, 16 \mathrm{~h}$.

Interestingly, when cyclohexyl methyl ketone was used as substrate, improved enantioselectivities were achieved. Here, the benzyl (L3b) and the phenyl (L4a) substituted oxamide ligands gave 53\% and $82 \%$ ee, respectively (Table 1 , entries 6 and 8). To elucidate the influence of the free $\mathrm{OH}$ group, ligands $\mathbf{L} \mathbf{4 b}$ and $\mathbf{L} \mathbf{5}$ were tested, producing racemic 1-cyclohexylethanol in low conversion. The phosphoruscontaining ligands L2a-c were also applied, with the aliphatic ketone showing no reactivity at all. Clearly, the in situ generated Mn catalyst system using oxamide ligand L4a is especially suited for ATH of aliphatic ketones and was chosen for further optimization of the reaction parameters.

Next to temperature and time (see the Supporting Information) different metal precursors such as $\operatorname{Mn}(0), \operatorname{Mn}(\mathrm{I})$ and $\mathrm{Mn}$ (II) salts were investigated to improve the catalyst activity and product yield (Figure 2 and Table S1). Besides $\left[\mathrm{MnBr}(\mathrm{CO})_{5}\right]$, especially $\left[\mathrm{Mn}_{2}(\mathrm{CO})_{10}\right]$ and $\left[\mathrm{Mn}(\mathrm{OTf})(\mathrm{CO})_{5}\right]$ produced the chiral alcohol in high enantiomeric excess of $76 \%$ and $84 \%$ ee. The tested Mn(II) precursors did not convert cyclohexyl methyl ketone under the applied conditions.

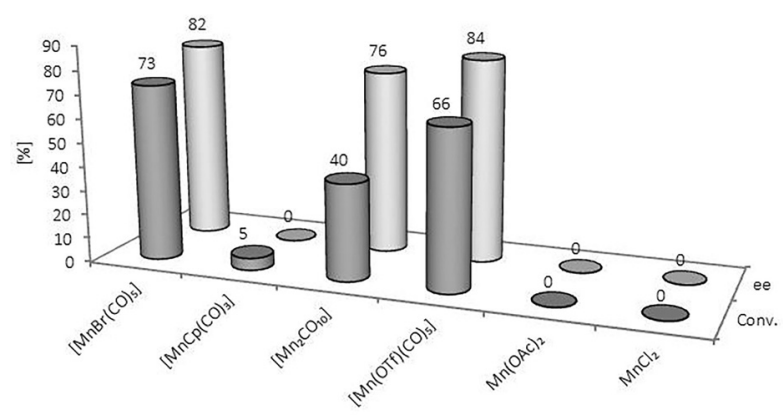

Figure 2 Metal precursor screening for ATH of cyclohexyl methyl ketone 
The influence of the other metal precursors in the in situ catalyst system was also studied in the ATH reaction of cyclohexyl methyl ketone under the optimized conditions. Applying different iron and ruthenium salts, 95\% conversion of the model substrate was achieved by combining dichloro( $p$-cymene)ruthenium(II) dimer with L4a. The tested iron precursors showed no activity at all for the desired reaction (see the Supporting Information). Notably, none of the tested noble metal precursors led to a higher selectivity compared with the results of the catalyst system generated from $\left[\mathrm{MnBr}(\mathrm{CO})_{5}\right]$ and $\mathbf{L 4 a}$. This is one of the rare cases in which a non-noble metal-based catalyst leads to higher enantioselectivities than its noble-metal analogues.

The influence of the metal to ligand to base ratios $(\mathrm{M} / \mathrm{L} / \mathrm{B})$ and loadings were then investigated. For the aliphatic benchmark substrate the initial ratio of $\mathrm{M} / \mathrm{L} / \mathrm{B}=$ $1: 1: 10$ yielded $48 \%$ of the product after $20 \mathrm{~h}$ at $80{ }^{\circ} \mathrm{C}$ (Table 2 , entry 1). To our surprise, with 2 or $5 \mathrm{~mol} \%$ metal and ligand loadings at a constant base loading (10 mol\%) no conversion of the substrate was observed (entries 2 and 3 ). Apparently, the amount of base is not sufficient to activate the catalytic systems, which demonstrates the importance of the free base for general reactivity.

Table 2 Optimization of M/L/B Ratio

\begin{tabular}{|c|c|c|c|c|}
\hline Entry & {$\left[\mathrm{MnBr}(\mathrm{CO})_{5}\right][\mathrm{mol} \%]$} & M:L:B & Conv. [\%] & ee [\%] \\
\hline 1 & 1 & $1: 1: 10$ & 48 & 82 \\
\hline 2 & 2 & $1: 1: 5$ & 0 & - \\
\hline 3 & 5 & $1: 1: 2$ & 0 & - \\
\hline 4 & 2 & $1: 1: 10$ & 73 & 83 \\
\hline 5 & 4 & $2: 1: 10$ & 80 & 86 \\
\hline 6 & 6 & $3: 1: 10$ & 84 & 88 \\
\hline 7 & 8 & $4: 1: 10$ & 65 & 90 \\
\hline 8 & 10 & $5: 1: 10$ & 0 & - \\
\hline
\end{tabular}

a Standard reaction conditions: ketone $(1 \mathrm{mmol}),\left[\mathrm{MnBr}(\mathrm{CO})_{5}\right]$, ligand, $\mathrm{KOtBu}, \mathrm{iPrOH}(6 \mathrm{~mL}), 70^{\circ} \mathrm{C}, 16 \mathrm{~h}$.

On the other hand, formation of the desired alcohol was achieved in significantly higher yield (73\%), when the amounts of metal, ligand and base were doubled (Table 2 , entry 4 ). The highest yield of $84 \%$ and a very good ee was observed with $6 \mathrm{~mol} \%$ loading of the metal precursor [Mn$\mathrm{Br}(\mathrm{CO})_{5}$ ] as an optimum (entry 6). A further increase of the metal loading led to decreased yields, although up to $90 \%$ ee was detected (entries 7 and 8). This rather unusual metal to ligand ratio raised the question of the real coordination mode of the ligand to the metal. NMR spectroscopy and mass spectrometry did not provide an insight into the coor- dination mode of the catalyst. Attempts to grow crystals were unsuccessful because of the propensity of oxamide ligands to form hydrogels. ${ }^{16}$ Therefore, the real nature of this in situ formed catalyst remains unclear.

With the optimized conditions in hand, ${ }^{17}$ the general catalytic activity of the catalyst system was explored for the ATH for 15 prochiral ketones (Scheme 1). Given the good results obtained with the cyclic aliphatic model substrate, other cyclic ketones were considered as a priority. While cyclopropyl methyl ketone (1) gave only $46 \%$ yield and $59 \%$ $e e$, cyclic ketones with increasing ring size (2-4) were reduced in good yields and high enantioselectivities of up to $88 \%$ ee. Furthermore, the influence of functional groups on the cyclohexyl ring was investigated. Thus, the heterocyclic 4-acetyltetrahydropyran (5) was transformed with a high yield $(88 \%)$ and excellent selectivity of $93 \% e e$. The $\alpha, \beta$-unsaturated 1-acetyl-1-cyclohexene (6) was chemoselectively reduced to the desired 1-(1-cyclohexenyl)ethanol but only with poor yield $(23 \% ; 74 \%$ ee). Attempts to improve the yield with longer reaction time $(48 \mathrm{~h})$ led to the respective saturated alcohol. Moreover, 1-tetralol was obtained in 35\% yield with $50 \%$ ee. Additionally, the linear aliphatic ketone 8 was converted in $63 \%$ yield into the desired alcohol with an $e e$ of $85 \%$. The branched ketone 1,1-diphenyl-2-propanone $(\mathbf{9})$ reacted only in moderate yield but with excellent selectivity of $92 \%$ ee.

Although the initial results with the aromatic model ketone were not very promising, a number of substituted acetophenones were applied in the manganese-catalyzed ATH. The para-substituted derivatives $\mathbf{1 0}$ and $\mathbf{1 1}$ were both reduced to the corresponding alcohols with 55\% ee. p-Methyl acetophenone (12) and 0 -methoxy acetophenone (13) were converted into the respective products with decreased yields and moderate chiral induction. Finally, the catalyst system $\left[\mathrm{MnBrCO}_{5}\right] / \mathbf{L} \mathbf{4 a}$ was also active for the transfer hydrogenation of the heterocyclic ketones 4-acetylpyridine (14) and 2-acetylfuran (15) with moderate yields and enantioselectivities.

In summary, we have developed a convenient protocol for asymmetric transfer hydrogenation of ketones derived from manganese and readily available $N, N^{\prime}$-bis(2-hydroxyethyl)oxamide ligands. The in situ generated catalyst system $\left[\mathrm{MnBrCO}_{5}\right] / \mathbf{L} \mathbf{4} \mathbf{a}$ is especially active for the reduction of aliphatic ketones with up to $93 \%$ ee. Although this ligand class is scarcely explored, its combination with manganese(I) precursors represents a potential alternative to established noble-metal catalysts based on chiral phosphorus containing ligands. Further work to generalize this concept and to determine the actual nature of the formed catalyst is under way.

\section{Funding Information}

This work was supported by the state of Mecklenburg Vorpommern. 

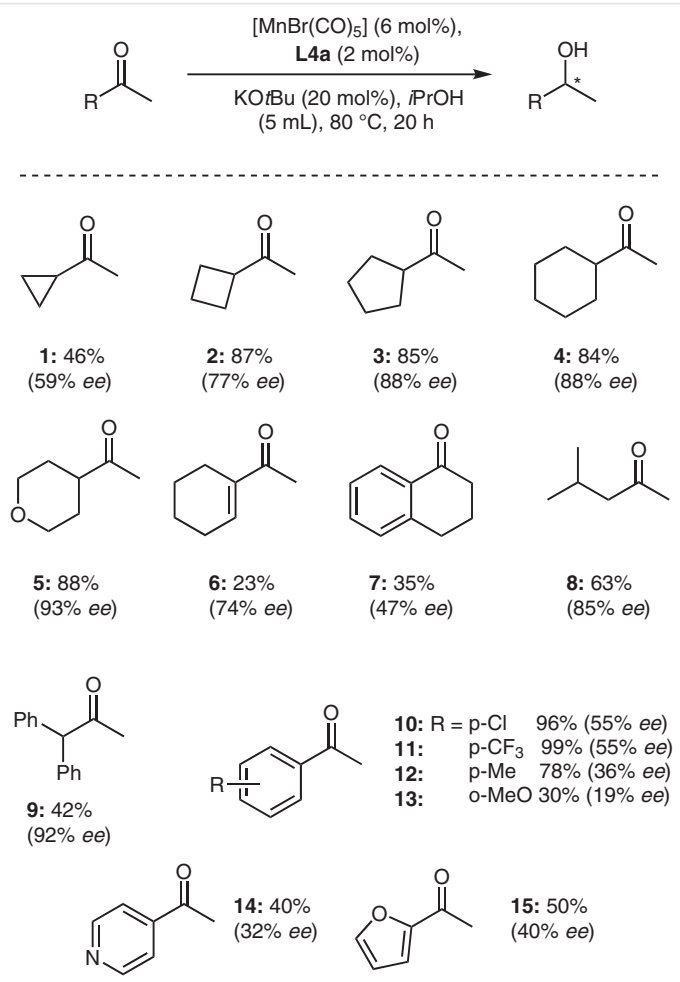

Scheme 1 Substrate scope for the ATH of ketones

\section{Acknowledgment}

We thank Dr. C. Fischer, S. Buchholz, S. Schareina and E. GerovaMartin (all at LIKAT) for their excellent technical and analytical support.

\section{Supporting Information}

Supporting information for this article is available online at https://doi.org/10.1055/s-0037-1611669.

\section{References and Notes}

(1) For recent reviews on iron-catalysed ATH of ketones, see: (a) Morris, R. H. Acc. Chem. Res. 2015, 48, 1494. (b) Bigler, R.; Huber, R.; Mezzetti, A. Synlett 2016, 27, 831. (c) Prokopchuk, D. E.; Smith, S. A. M.; Morris, R. H. In Ligands for Iron-Based Homogeneous Catalysts for the Asymmetric Hydrogenation of Ketones and Imines; John Wiley \& Sons, Ltd: Weinheim, 2016, pp. 20.

(2) (a) Demmans, K. Z.; Ko, O. W. K.; Morris, R. H. RSC Adv. 2016, 6, 88580. (b) De Luca, L.; Mezzetti, A. Angew. Chem. Int. Ed. 2017, 56, 11949. (c) Demmans, K. Z.; Seo, C. S. G.; Lough, A. J.; Morris, R. H. Chem. Sci. 2017, 8, 6531. (d) Bigler, R.; Mezzetti, A. Org. Process Res. Dev. 2016, 20, 253. (e) Zuo, W.; Lough, A. J.; Li, Y. F.; Morris, R. H. Science 2013, 342, 1080. (f) Bigler, R.; Mezzetti, A. Org. Lett. 2014, 16, 6460. (g) Bigler, R.; Huber, R.; Mezzetti, A. Angew. Chem. Int. Ed. 2015, 54, 5171. (h) Bigler, R.; Huber, R.;
Stöckli, M.; Mezzetti, A. ACS Catal. 2016, 6, 6455. (i) De Luca, L.; Mezzetti, A. Angew. Chem. Int. Ed. 2017, 56, 11949. (j) De Luca, L.; Mezzetti, A. CHIMIA 2018, 72, 233.

(3) Li, Y.-Y.; Yu, S.-L.; Shen, W.-Y.; Gao, J.-X. Acc. Chem. Res. 2015, For a recent review on ATH including cobalt, see: 48, 2587.

(4) Zhang, G.; Hanson, S. K. Chem. Commun. 2013, 10151.

(5) For recent reviews on manganese-catalysed (de)hydrogenative reactions, see: (a) Maji, B.; Barman, M. K. Synthesis 2017, 49, 3377. (b) Garbe, M.; Junge, K.; Beller, M. Eur. J. Org. Chem. 2017, 4344. (c) Kallmeier, F.; Kempe, R. Angew. Chem. Int. Ed. 2018, 57, 46; Angew. Chem. 2018, 130, 48.

(6) (a) Elangovan, S.; Topf, C.; Fischer, S.; Jiao, H.; Spannenberg, A.; Baumann, W.; Ludwig, R.; Junge, K.; Beller, M. J. Am. Chem. Soc. 2016, 138, 8809. (b) Elangovan, S.; Garbe, M.; Jiao, H.; Spannenberg, A.; Junge, K.; Beller, M. Angew. Chem. Int. Ed. 2016, 55, 15184. (c) Kallmeier, F.; Irrgang, T.; Dietel, T.; Kempe, R. Angew. Chem. Int. Ed. 2016, 55, 11806. (d) van Putten, R.; Uslamin, E. A.; Garbe, M.; Liu, C.; Gonzalez-de-Castro, A.; Lutz, M.; Junge, K.; Hensen, E. J. M.; Beller, M.; Lefort, L.; Pidko, E. A. Angew. Chem. Int. Ed. 2017, 56, 7679. (e) Garbe, M.; Junge, K.; Walker, S.; Wei, Z.; Jiao, H.; Spannenberg, A.; Bachmann, S.; Scalone, M.; Beller, M. Angew. Chem. Int. Ed. 2017, 56, 11237. (f) Papa, V.; Cabrero-Antonino, J. R.; Alberico, E.; Spannenberg, A.; Junge, K.; Junge, H.; Beller, M. Chem. Sci. 2017, 8, 3576. (g) Espinosa-Jalapa, N. A. Nerush A.; Shimon, L. J. W.; Leitus, G.; Avram, L.; Ben-David, Y.; Milstein, D. Chem. Eur. J. 2017, 23, 5934. (h) Fu, S.; Shao, Z.; Wang, Y.; Liu, Q.J. Am. Chem. Soc. 2017, 139, 11941. (i) Glatz, M.; Stöger, B.; Himmelbauer, D.; Veiros, L. F.; Kirchner, K. ACS Catal. 2018, 8, 4009. (j) Kumar, A.; Janes, T.; Espinosa-Jalapa, N. A.; Milstein, D. Angew. Chem. Int. Ed. 2018, 57, 12076. (k) Zou, Y.-Q.; Chakraborty, S.; Nerush, A.; Oren, D.; Diskin-Posner, Y.; Ben-David, Y.; Milstein, D. ACS Catal. 2018, 8, 8014.

(7) (a) Perez, M.; Elangovan, S.; Spannenberg, A.; Junge, K.; Beller, M. ChemSusChem 2017, 10, 83. (b) Bruneau-Voisine, A.; Wang, D.; Dorcet, V.; Roisnel, T.; Darcel, C.; Sortais, J.-B. Org. Lett. 2017, 19, 3656.

(8) Zirakzadeh, A.; de Aguiar, S. R. M. M.; Stöger, B.; Widhalm, M.; Kirchner, K. ChemCatChem 2017, 9, 1744.

(9) Demmans, K. Z.; Olson, M. E.; Morris, R. H. Organometallics 2018, 37, 4608.

(10) Wang, D.; Bruneau-Voisine, A.; Sortais, J.-B. Catal. Commun. 2018, 105, 31 .

(11) (a) Widegren, M. B.; Harkness, G. J.; Slawin, A. M. Z.; Cordes, D. B.; Clarke, M. L. Angew. Chem. Int. Ed. 2017, 56, 5825. (b) Garbe, M.; Junge, K.; Walker, S.; Wie, Z.; Jiao, H.; Spannenberg, A.; Bachmann, S.; Scalone, M.; Beller, M. Angew. Chem. Int. Ed. 2017, 56, 11237; Angew. Chem. 2017, 129, 11389.

(12) Ligands L3b, L4a, L4b, L5, L6a and L6b were synthesized analogously to procedures described for related compounds, see: Şeker, S.; Barış, D.; Arslan, N.; Turgut, Y.; Pirinççioğlu, N.; Toğrul, M. Tetrahedron: Asymmetry 2014, 25, 411; To a solution of the corresponding amino alcohol $(2 \mathrm{mmol})$ in $\mathrm{MeOH}(4 \mathrm{~mL})$ was added a solution dimethyl oxalate $(1 \mathrm{mmol})$ in $\mathrm{MeOH}(2 \mathrm{~mL})$ dropwise at room temperature. The resulting mixture was stirred for $30 \mathrm{~min}$. Within this time, a cloudy white solid was formed. The solid was filtered off and washed with cold $\mathrm{MeOH}$ $(2 \times 2 \mathrm{~mL})$ to give the analytically pure product. Analytical data found for $L \mathbf{4 b}$ ${ }^{1} \mathrm{H}$ NMR $\left(300 \mathrm{MHz}\right.$, DMSO- $\left.d_{6}\right): \delta=7.96(\mathrm{~d}, J=8.2 \mathrm{~Hz}, 2 \mathrm{H}), 7.29$ $7.19(\mathrm{~m}, 10 \mathrm{H}), 5.07-4.98(\mathrm{~m}, 2 \mathrm{H}), 3.60$ (d, J = 5.3 Hz, $4 \mathrm{H}), 3.29$ $(\mathrm{s}, 6 \mathrm{H}) \cdot{ }^{13} \mathrm{C}$ NMR $\left(75 \mathrm{MHz}, \mathrm{DMSO}-d_{6}\right): \delta=159.30,138.50$, 
128.66, 127.88, 126.86, 74.79, 59.12, 53.50.MS (ESI-TOF): $\mathrm{m} / \mathrm{z}$ calcd $357.1814[\mathrm{M}+\mathrm{H}]^{+}, 379.1627[\mathrm{M}+\mathrm{Na}]^{+}$; found: 357.1804 $[\mathrm{M}+\mathrm{H}]^{+}, 379.1627[\mathrm{M}+\mathrm{Na}]^{+}$.

L5

${ }^{1} \mathrm{H}$ NMR $\left(300 \mathrm{MHz}\right.$, DMSO- $\left.d_{6}\right): \delta=9.07(\mathrm{~d}, J=9.0 \mathrm{~Hz}, 2 \mathrm{H}), 7.41-$ $7.10(\mathrm{~m}, 10 \mathrm{H}), 4.79-4.56(\mathrm{~m}, 2 \mathrm{H}), 2.03-1.60(\mathrm{~m}, 4 \mathrm{H}), 0.82(\mathrm{t}$, $J=7.3 \mathrm{~Hz}, 6 \mathrm{H})$.

${ }^{13} \mathrm{C}$ NMR (75 MHz, DMSO- $\left.d_{6}\right): \delta=159.69,142.88,128.20$, 126.89, 126.73, 54.99, 28.22, 11.20.MS (ESI-TOF): $\mathrm{m} / \mathrm{z}$ calcd $347.1730[\mathrm{M}+\mathrm{Na}]^{+}$; found: $347.1727[\mathrm{M}+\mathrm{Na}]^{+}$.

\section{L6a}

${ }^{1} \mathrm{H}$ NMR $\left(300 \mathrm{MHz}\right.$, DMSO- $\left.d_{6}\right): \delta=8.86(\mathrm{~d}, 2 \mathrm{H}), 7.38-7.03(\mathrm{~m}$, $20 \mathrm{H}), 5.06-4.91$ (m, $2 \mathrm{H}), 4.91-4.81(\mathrm{~m}, 2 \mathrm{H})$.

${ }^{13} \mathrm{C}$ NMR $\left(75 \mathrm{MHz}\right.$, DMSO- $\left.d_{6}\right): \delta=159.74,140.25,128.16$, 127.05, 127.01, 63.95, 55.74.MS (ESI-TOF): $\mathrm{m} / \mathrm{z}$ calcd 503.1941 $[\mathrm{M}+\mathrm{Na}]^{+}$; found: $503.1945[\mathrm{M}+\mathrm{Na}]^{+}$.

L6b

${ }^{1} \mathrm{H}$ NMR (300 MHz, DMSO- $d_{6}$ ): $\delta=8.90-8.68(\mathrm{~m}, 2 \mathrm{H}), 7.41-7.05$ $(\mathrm{m}, 20 \mathrm{H}), 5.03-4.74(\mathrm{~m}, 4 \mathrm{H})$.

${ }^{13} \mathrm{C}$ NMR (75 MHz, DMSO- $d_{6}$ ): $\delta=158.99,142.87,140.13$, $128.60,128.05,127.54,127.36,127.09,74.10,59.46,74.10$, 59.46.

MS (ESI-TOF): $\mathrm{m} / \mathrm{z}$ calcd $503.1941[\mathrm{M}+\mathrm{Na}]^{+}$; found 503.1949 $[\mathrm{M}+\mathrm{Na}]^{+}$.

(13) Ligands L3a, L3c, and $\mathbf{L 7}$ were synthesized analogously to the procedure described for related compounds, see: Woods, B. P.; Orlandi, M.; Huang, C. Y.; Sigman, M. S.; Doyle, A. G. J. Am. Chem. Soc. 2017, 139, 5688; The corresponding amino alcohol (1 $\mathrm{mmol}$ ) and dimethyl oxalate $(1 \mathrm{mmol})$ were added under a flow of argon into a flame-dried $25 \mathrm{~mL}$ Schlenk tube containing a PTFE-coated stirring bar. Toluene $(10 \mathrm{~mL})$ was added by using a syringe and the suspension was heated to $90{ }^{\circ} \mathrm{C}$. After $3 \mathrm{~h}$, the mixture was allowed to cool to room temperature and the volatiles were removed in vacuo. The resulting solid was washed with cold toluene $(2 \times 2 \mathrm{~mL})$ to give the analytically pure product.

Analytical data found for $\mathrm{L} 3 \mathrm{C}$

${ }^{1} \mathrm{H}$ NMR: $\delta=8.05$ (d, $\left.J=9.8 \mathrm{~Hz}, 2 \mathrm{H}\right), 3.74-3.40(\mathrm{~m}, 6 \mathrm{H}), 0.87$ (s,
$18 \mathrm{H}) .{ }^{13} \mathrm{C}$ NMR $\left(75 \mathrm{MHz}\right.$, DMSO- $\left.d_{6}\right): \delta=160.21,59.90,59.41$, 33.93, 26.86.MS (ESI-TOF): $m / z$ calcd $289.2127 \quad[\mathrm{M}+\mathrm{H}]^{+}$, $311.1941[\mathrm{M}+\mathrm{Na}]^{+}$; found: $289.2120[\mathrm{M}+\mathrm{H}]^{+}, 311.1944[\mathrm{M}+\mathrm{Na}]^{+}$. L7

${ }^{1} \mathrm{H}$ NMR (300 MHz, DMSO- $d_{6}$ ): $\delta=9.10$ (s, $2 \mathrm{H}$ ), 7.30-6.94 (m, 8 H), 5.16-5.03 (m, $2 \mathrm{H}), 4.58-4.41(\mathrm{~m}, 2 \mathrm{H}), 3.21-3.12(\mathrm{~m}, 2 \mathrm{H})$, 2.78-2.69 ( $\mathrm{m}, 2 \mathrm{H})$.

${ }^{13} \mathrm{C}$ NMR: $\left(75 \mathrm{MHz}\right.$, DMSO- $\left.d_{6}\right): \delta=160.60,141.16,139.79$, $127.66,126.63,124.66,123.59,76.91,61.43,40.20$ (shoulder of DMSO signal) MS (ESI-TOF): $m / z$ calcd $352.1423[\mathrm{M}]^{+}$; found: $352.1429[\mathrm{M}]^{+}$.

(14) Denmark, S. C.; Stavenger, R. A.; Faucher, A.-M.; Edwards, J. P. J. Org. Chem. 1997, 62, 3375.

(15) Gao, J.-X.; Ikariya, T.; Noyori, R. Organometallics 1996, 15, 1087.

(16) (a) Makarević, J.; Jokić, M.; Raza, Z.; Štefanić, Z.; Kojić-Prodić, B.; Žinić, M. Chem. Eur. J. 2003, 9, 5567. (b) Dzolic, Z.; Wolsperger, K.; Zinic, M. New J. Chem. 2006, 30, 1411. (c) Sunkur, M.; Baris, D.; Hosgoren, H.; Togrul, M. J. Org. Chem. 2008, 73, 2570.

(17) General procedure for the ATH of prochiral ketones: Ligand L4a (6.6 mg, $0.02 \mathrm{mmol}, 2 \mathrm{~mol} \%$ ) and $\operatorname{MnBr}(\mathrm{CO})_{5}(16.2 \mathrm{mg}, 0.06$ mmol, $6 \mathrm{~mol} \%$ ) were placed in a flame-dried $25 \mathrm{~mL}$ Schlenk tube equipped with a PTFE-coated stirring bar, followed by anhydrous degassed isopropyl alcohol $(2 \mathrm{~mL})$. The suspension was stirred for $10 \mathrm{~min}$ at room temperature. A solution of potassium tert-butoxide ( $22.4 \mathrm{mg}, 0.2 \mathrm{mmol}, 20 \mathrm{~mol} \%$ in $2 \mathrm{~mL} i \mathrm{PrOH}$ ) was added and the resulting yellowish solution was stirred for a further $10 \mathrm{~min}$ at room temperature. A solution of the desired ketone ( $1 \mathrm{mmol}$ in $2 \mathrm{~mL} i \mathrm{PrOH}$ ) was then added and the mixture was heated to $80^{\circ} \mathrm{C}$ and kept at this temperature for $20 \mathrm{~h}$. The reaction solution was allowed to cool to room temperature and filtered through a plug of silica and washed with $i \mathrm{PrOH}(3 \times 5$ $\mathrm{mL})$. Hexadecane $(20 \mathrm{mg})$ was added to the reaction solution. The yield of the desired alcohol was determined by GC analysis using hexadecane as internal standard, and the ee was determined either by GC or HPLC analysis using an appropriate separation method (see the Supporting Information for further information). 